\title{
Spirituality, silence and solitude: A reflective interpretation regarding mystery and people with nonverbal autism
}

\author{
Karenne Hills, Jayne Clapton and Pat Dorsett \\ School of Human Services and Social Work, Griffith University, Brisbane, Australia
}

\begin{abstract}
People with severe (nonverbal) autism are considerably underresearched and misunderstood. This is despite the number of diagnoses growing at epidemic proportions. Approximately 30\% of people with autism are placed on the severe end of the spectrum, demonstrating social communication issues and severe speech deficits. This paper provides a reflection concerning the findings of a research study that explored the spirituality of people with barriers to traditional religious exposure, through the context of people with nonverbal autism. Spirituality and autism is a relatively new discipline, with scant information available pertaining to those with severe autism. Yet the humanness of this group, underpinned by the theological premise that values all people as carriers of the Imago Dei, is worthy of consideration. The traditional mystical disciplines of silence and solitude as enhancing spiritual awareness are explored alongside the life context that accompanies severe autism. Heightened sensitivity to sensory input typical of the condition is thought to be relevant to more subjective perceptions such as atmospheric changes and spiritual aptitude. Research data relaying unusual spiritual perception and experiences were confirmed by a number of works authored by people with nonverbal autism. This suggests the possibility that the life context of this population can be seen as conducive to spiritual aptitude rather than as a neurological deficit.
\end{abstract}

\section{KEYWORDS}

Spirituality; nonverbal autism; theology; language; silence; mystery

\section{Introduction}

Autism is known as a spectrum disorder, with a long variation in severity and expression. Those with the most severe form of autism present with pronounced hyper/hypo sensitivity, poor dexterity, social communication challenges and little or no oral speech (see American Psychiatric Association [2013] for diagnostic criteria). People with nonverbal autism are identified as being on the severe end of the spectrum. Current statistics estimate that 1 in 59 children in the U.S.A. is diagnosed with autism (Centers for Disease Control and Prevention 2018). Approximately $30 \%$ of overall diagnoses are considered severe, with these individuals unlikely to develop functional speech (Jack and Pelphrey 2017). Even 
though vast advancements in knowledge about autism over the past 50 years are evident, little information exists concerning people with severe autism.

We acknowledge the appropriateness of person-first language as a term of reference for certain groups of people. As this paper specifically refers to a particular population who are diagnostically placed on the severe end of the autism spectrum and is particularly focused on issues relevant to language and speech, we use the term 'people with nonverbal autism'. This term regards the dignity and preference expressed by participants of the research study, and by the wider autism community (Kenny et al. 2016).

The absence of oral language creates many challenges for people with nonverbal autism and those who strive to understand them. Such language deficits also create significant barriers to inclusive research (Siegel 2018). Thus, this population is severely under-researched (Jack and Pelphrey 2017), particularly regarding spirituality. Furthermore, people with nonverbal autism are subject to societal misconceptions that render them a largely voiceless, isolated and marginalised group. As diagnostic rates continue to increase (Blumberg et al. 2013) and public awareness grows, one constant remains - autism is a mysterious condition, with much yet to discover about its impact on the lives of those it touches.

Spirituality, by definition, is another mysterious and complex element of the human experience (Lepherd 2015). The subjective and personal nature of spirituality ideally opens opportunity for individual perspectives concerning particular approaches (Hills, Clapton, and Dorsett 2019). Influences such as culture, philosophy and religion impact upon how it is conceptualised, experienced and expressed from person to person (Reinert and Koenig 2013). Therefore, spirituality can be understood as inherent to the human experience whether cognitively acknowledged or not (Tacey 2015) and may be encountered independently from traditional religious teaching (Barber 2016).

\section{Spirituality in the context of nonverbal autism: A research study}

This paper presents part of a research study titled 'Spirituality in the context of nonverbal autism'. It offers a personal interpretation pertaining to the findings of the study, as conceptualised by the first author. Data sourced from participant interviews are explored alongside theological, traditional and relevant contemporary thinking, to draw together suggestions for considered reflection regarding spirituality amongst people whose life context excludes typical social interaction. Broadly speaking, the study of spirituality and autism is still in its inception (Barber 2016; Bogdashina 2013; Isanon 2001; Swinton 2012). Empirical literature pertaining to spiritual considerations specific to people with nonverbal autism however, is negligible (Hills, Clapton, and Dorsett 2016). There is, nevertheless, some relevant 'grey literature' consisting of a small number of publications authored/co-authored by people with nonverbal autism (Ball 1999, 2001; Bonker and Breen 2011; Burns and Wambua 2009; Cochran 2011; Cullen and Ricker 2016; Goddard and Goddard 2012; Hale and Hale 1999; Lee and Marquez 2011; McKinley 2011; Rocha and Jorde 1995; Weirauch 2013).

These works were valuable to this study as they represented the only information available that exemplified the spiritual perspectives of people with nonverbal autism. As such, this collection was included in a Scoping Literature Review relevant to the study and titled the 'nonverbal narrative' literature to respect the voices of the people it represented (Hills, Clapton, and Dorsett 2016). 


\section{Designing a methodology}

An objective of the research was to design a methodology that would respect and include the narratives of people with nonverbal autism. As such, this study has shown that research using people with nonverbal autism as direct respondents is not only possible, but a highly effective way to source data from a previously under-researched population. An approach that permitted data collection from an inclusive, first-hand perspective rather than from a second-hand source such as a parent or teacher, was paramount to the authenticity of the study. To achieve this aim ethically and with methodological rigour meant respecting the chosen method of communication for each interviewee.

\section{Research participants}

There were six Australian participants, and one American, aged between 23 and 53. The Australians were recruited from a literary club for people who are nonverbal, and the American at an international disability conference. Two participants had some religious affiliation through their family, one from a Christian tradition and the other Jewish, with the other five reporting no religious background.

\section{Interview as a successful method of data collection}

People who are unable to use oral language often communicate by a personalised letter board or electronic device. Dexterity issues mean that users of such devices often require the support of a communication facilitator. This process is known as Facilitated Communication (FC) or Facilitated Communication Training (FCT). Participants of this study were all proficient in the use of FC, which represented their only way of meaningfully imparting information. Seven participants utilised six different facilitators for separately conducted interviews, yet analysis of data demonstrated remarkable consistency even though some participants and their facilitators were unknown to others. Whilst outside the scope of this paper to discuss in detail, the process was approved by the relevant institutional Human Research Ethics Committee prior to the commencement of the study.

Findings revealed that spirituality was conceptualised within the framework of participants' typical lived experiences, which included limited social opportunities and minimal or no oral communication. This theme was also dominant in the nonverbal narrative literature (Hills, Clapton, and Dorsett 2016). A sophisticated and dynamic approach to spirituality was evidenced, with transcendent experiences and encounters well represented. The relevance of these findings will be discussed throughout this paper.

This research also challenged societal misconceptions assuming that people with nonverbal autism are intellectually incompetent and socially unaware. For instance, the assumption that a lack of oral language equates to low intelligence was clearly discredited, with all participants demonstrating keen cognitive and emotional intelligence. For example:

We are intelligent people with all the same issues and desires as everyone else. I would like to be able to use my intelligence to work and contribute to society. I am very intelligent, but I can't really utilize this in a constructive way. I wish I had a more normal brain and things were easier. (Participant 1) 
The nonverbal narrative literature also provided a strong oppositional theme concerning societal misconceptions about people with nonverbal autism. Many authors expressed the desire to be recognised as intelligent and able to contribute to human understanding (Ball 1999, 2001; Bonker and Breen 2011; Burns and Wambua 2009; Cochran 2011; Cullen and Ricker 2016; Fleischmann and Fleischmann 2012; Goddard and Goddard 2012; Hale and Hale 1999; Lee and Marquez 2011; McKinley 2011; Rocha and Jorde 1995; Weirauch 2013).

\section{Societal constructs concerning language and speech}

Essentially, the world revolves around language, whether spoken or written (Grandin 2011). Language is understood as 'a culturally defined code (i.e. set of arbitrary symbols) whereby ideas are conveyed for the purpose of communication' (Stone and Yoder 2001, 341), with spoken communication the oral expression of this code. Typical language authenticates interpretations between the initiating and receiving of messages between people (Pinchevski 2005).

Relevant scholarly literature identifies speech and language as separate human functions (Norbury et al. 2016). As such, language is not necessarily impaired in people with certain speech deficits. Put simply, a person may know what they would like to say but may be unable to coordinate the necessary functions to translate their thoughts into spoken words (Biklen 1993; Vosseller 2018). Such is the experience of persons with nonverbal autism (Biklen 2005). Individuals may differ in their ability and opportunity for language expression, from those with no scope for meaningful communication other than behavioural responses, to those with minimal verbalisation of words and short phrases. However, communication issues are not necessarily due to the inability for expression, but rather in the inability of others to recognise and translate certain behaviours (Fleischmann and Fleischmann 2012; Goddard and Goddard 2012; Hills, Clapton, and Dorsett 2016). This misunderstanding impedes the ability of people with nonverbal autism to access strategies for purposeful communication. Participants in this research were either nonverbal or minimally verbal yet contributed rich and detailed data via their preferred communication device in response to interview questions.

\section{Autism and the language of God}

Whilst perhaps not the preferred approach of all believers, this research was underpinned by the theological premise that respects the inherent value and worth of all human beings as carriers of the Imago Dei, that is, created in the image of God (Hills, Clapton, and Dorsett 2019; Hills and Meteyard 2013). In the context of this discussion, one is called to deeper consideration of how the concept of Imago Dei relates to those with autism. Theologically, it has been suggested that the image of God manifests in certain elements of humanness such as relationality and love (Swinton 2012). It has also been argued, however, that contemporary conceptualisations concerning such aspects of humanness are subjective, culturally informed, and open to personal interpretation and experience. Regarding people with autism, these elements are often believed to be diminished or absent (Bustion 2017; Swinton 2012). This belief invites deeper contemplation as to 
how God's image may be reflected amongst this group specifically, and amongst all humans in relation to the autistic expression.

The experience and expression of love is arguably an individual and personal encounter. By way of illustration, I (first author) have an adult son with autism, who expresses love very differently to me. However, when he sits on the floor next to my bed (he would never sit in the bed with me because that would be far too close) and thanks me for helping him with something, or giving him some direction, I know he is saying he loves me. We laugh together and tease each other; however hugs are rare and relatively wooden when I can persuade him to have one. Love is present and expressed in our acceptance and respect for each other's difference rather than by more traditional ways. Furthermore, it is never a token expression from him - when it comes it is genuinely offered. We enjoy a mutually invested relationship, although it is unlike any I observe between other parents and their adult children.

Although a personal anecdote, this exemplifies an experience that defies common misconceptions regarding the inability of people with autism to maintain relationships and to experience and express love. Research findings also refute this assertion amongst people with severe autism, as is demonstrated by one participant in reference to his nonverbal friends:

We are all together on this journey of life and we can communicate so it's a completely different story now and we will go on together and love and laugh and be as best as best as we can in the way of helping our fellow passengers and the environment. (Participant 3)

The desire and ability for meaningful relationships amongst people with nonverbal autism is also represented in the nonverbal narrative literature (Bonker and Breen 2011; Goddard and Goddard 2012; Lee and Marquez 2011). Carly Fleischman described her typical childhood memories - so rich in relationship - in this way: 'one thing I enjoyed the most is listening to my dad read me stories in bed' and 'crawling into my sister's bed at night after I woke up and she let me sleep with her. She cuddled me till I fell asleep. I'm lucky to have her' (Fleischmann and Fleischmann 2012, 234).

Relationships and love may be expressed differently amongst people with autism, however this should not be used to infer that relationships do not exist or are diminished (Brock 2009; Harshaw 2012). This discussion argues that the absence of audible speech may lead to a specific expression of spirituality. Perhaps the language of love and relationship that is the intrinsic reflection of God in humanity, is better communicated beyond words. Perhaps the image of God reflects a language of love that may be more easily accessed through a life experience with differences in language and socialisation. Furthermore, data from the research interviews provoke further contemplation concerning the spiritual interaction between silence, relationship and love.

\section{Spirituality, silence and nonverbal autism}

Historically there have been many explorations into human spirituality. Christian mystics such as St John of the Cross (Starr 2003), and Julian of Norwich (Jantzen 2000), prepared a legacy built on inner experience and silence as pathways for spirituality and Divine/ human encounters. Also known as the wisdom tradition, mystical dimensions of spirituality represented the transforming knowledge and experience of God, often accessed through the 
disciplines of silence and solitude. Contemplative styles of prayer and meditation are ancient practices which have been integral to spiritual formation within various religious persuasions. Early Christian writers viewed spiritual events as the very foundation of religious encounter. Trappist monk, Thomas Keating, maintained that only through the spiritual discipline of silence could anyone encounter the presence of God (The Economist 2018). He and his contemporary, Thomas Merton, taught methods of contemplative and centring prayer as basic requirements for self-exploration and Divine connection (Schiffhorst 2011). Keating espoused the personal benefits of such practices as resembling a type of divine psychotherapy that would purify the mind from conscious or unconscious emotional trauma (The Economist 2018). Comparably, Buddhist practices of mindfulness and loving kindness (Metta Bhavana), are foundational to the creation of personal and societal wellness and peace (Neeti 2015). Ancient Judaism also included meditative practices as approaches to prayer and Divine Connection. Such reflective prayers within Judaism are considered outside the use of words, likened to a sigh, murmur or muse (Barber 2016).

People with nonverbal autism often live isolated lives, with communication and social idiosyncrasies that create barriers to typical social engagement (Isanon 2001). In the context of spirituality, an analogy could be drawn from the experiences of the mystics, with silence and solitude as common ingredients (Stillman quoted in Rudy 2017). In this context, silence can be defined as 'forbearance from speech or noise' or 'the state of keeping or being silent'; and solitude as 'the quality or state of being alone or remote from society' (Merriam-Webster 2019a, 2019b).

It could be argued that a double standard emerges when the life experience of the person who pursues meditation, silence and other spiritual disciplines in order to achieve a certain 'spiritual plateau' is compared to the life context of someone with nonverbal autism (Stillman quoted in Rudy 2017, para. 7). By nature of their isolated life context, people with nonverbal autism live in a predominately silent (communication with the absence of spoken words) world, whereas mystics intentionally choose this same lifestyle in the pursuit of spiritual aptitude. This raises a question concerning the development of a similar spiritual awareness for people with nonverbal autism, consequent to their life context. Furthermore, it has been identified that people living without conventional language often hold an ability to relate to others beyond the need for typical speech (Isanon 2001). It is understood that from the depths of this type of silence, such people can meet with others at a similar deep and silent place, where a type of intuitive or perceptive listening becomes possible. This ability affords them a type of 'spiritual wealth' (Isanon 2001, 119), which can lead others to their own spirituality through meeting at this internal silent place (Isanon 2001; Rocha and Jorde 1995). This depth, whilst perhaps difficult to conceptualise for those without a communication deficit, is well documented in the nonverbal narrative literature, and in data from this research. For example:

I almost never use conventional language in spirituality. My spirit flows through my dance and feelings and music. My spirituality lets others experience my humanity. (Participant 7)

And another admitted:

'Yes, I feel people's energies.' (Participant 3)

With regards to her own daughter who is not verbal, Harshaw $(2012,312)$ described a similar phenomenon: '[...] her voice resonates loud and clear through each day 
of our lives. Rebecca speaks to us of many things but most of all she speaks to us of God'.

Categorically, spiritual experiences are deeply personal. The inability to communicate adequately the depth and meaning of such a subjective experience has been noted (Gandhi 2009). The writings of many Christian, American Indian (Hoffman 1997) and other traditional mystics also identify a common theme denoting profound spiritual experience as being conceptualised in a way that is beyond conventional language (Gandhi 2009; Keating 2005). Further, Yamane (2000) identified that humans are unable to experience and reflect simultaneously. Therefore, 'by the time a person can make sense of an experience and formulate it in words or thought, the experience has already passed' (Gandhi $2009,10)$. One might use their own internal 'self-talk' language to reflect upon and then eventually express a profound experience, yet also be aware that the experience is unable to be grasped or communicated with language.

It is suggested that the underpinning richness that has been discovered by those committed to mystical practices of contemplation as a means of heightened spiritual experiences comes from a similar process. The discipline of emptying the mind of words and thought appears to enable the mystic to draw towards a divine encounter (Bitton-Ashkelony 2012; Harmless 2008; Keating 2005; Underhill 2015). The mind is removed of words, pictures or impressions in order to feel the emptiness, which creates the space for a Divine encounter (Harmless 2008). It is the commitment to finding an experience of 'intentional inward and outward silence' (Campolo and Darling 2007, 129), that draws the mystic to Divine experience. One participant of this study expressed his own, similar internal process by way of a poem.

\section{Winged Wonder}

My soul is in the darkness

Huge infinite darkness

Pain was its diet

Pain was its fluid

Pain was its companion

Pain, only pain.

But somewhere in that blackness was a winged light;

A winged light that lit my soul.

It was there.

It was there.

It stayed and I endured.

And I emerged eventually

And so my soul and I journey on together -

On to the world and its joys and its happiness -

On, on, on.

[reproduced with the author's permission] 


\section{Spirituality and language}

Any study investigating the experiential dimension of spirituality should begin by considering the experience itself (Yamane 2000). The use of linguistic expressions to understand, interpret and communicate spiritual experiences renders the researcher only able to study the experience relative to the linguistic representations of the experience, rather than the actual experience. The outer expressions of an experience represent one's relationship with the world, external to the self. These interactions are observable and measurable. The inner, more intimate expressions of spirituality are representative of one's relationship with the transcendent, thus are far less observable (Lepherd 2015). Furthermore, spirituality can be seen to support transcendent experiences and concepts with certain language expressions beyond typical cognitive and verbal conveyance such as metaphor, symbolism and intuition (Hills, Clapton, and Dorsett 2019; Meji 2017).

The person with nonverbal autism, therefore, may well hold the ability to reflect and make meaning from a spiritual experience without the ability or need to express this experience in a typically understood way. Thus, if the meaning of the experience is not dependant on expression of conventional language per se, the recipient could be open to a heightened or extended experience simply because there is no requirement to source and construct linguistic representation to authenticate it. Language only becomes necessary when there is a need for expression of the experience. Thus, the ability for immediacy in an experience as it intensifies and emerges, without the distraction of sourcing language for interpretation, is not inconceivable. This ability, whether intentional or not, may open the way for new understanding concerning atypical expressions of spirituality. Such conceptualisation was identified by one research participant:

Spirituality is a difficult word because it is cultural. Can't see the same answer if one is in a culture where a religion is practiced formally by the whole population but in my case I think in flashes of colour and space so my perception of my links with something that is greater than me and core to existence must be different from the way people whose perception of self is driven by language. (Participant 5)

Similarly, from person to person, the language used for prayer becomes personal, and the speech or thoughts used will be symbolic and meaningful to the individual (Dearey 2009). Therefore, the relationship between spiritual experience and language is unique to the individual, which is relevant to people whose language and speech skills vary from typical expressions.

The human experience of internal dialogue is noteworthy in this context. It is identified as a common human experience that, when in solitude, an intimate conversation begins within that generally cannot stop. This conversation has been described as the need of the soul for satisfaction, a type of need that can only be satisfied by a Divine encounter (Pitre 2009). Therefore, spiritual experiences can be described as a step up, or transformation of that internal conversation that every person has with themselves. When the conversation with oneself is exhausted, in the absence of another person for feedback or further discourse it is suggested that it then becomes a conversation with God. This is because the human soul must converse with someone other than itself (Garrigou-Lagrange 2014; Pitre 2009). Logically, it could be assumed therefore, that a person with limited means for conventional conversation would naturally possess a spiritually rich inner dialogue facilitated by their unique life circumstance. This type of inner dialogue may well 
provide the necessary meeting place for a Divine encounter unique for someone with nonverbal autism, as is suggested by the mystical experience. Just like anyone else's, their soul seeks satisfaction beyond itself.

The ability of people with certain disabilities to compensate for their limitations with hyper-developed abilities in other physical and sensory functions is well documented; for example, someone who is visually impaired will often demonstrate acute hearing or better memory (Sorokowska and Karwowski 2017). Relevant to this discussion, differences in the human experience noted in people with nonverbal autism include the response to and processing of sensory stimuli, which manifests as extreme sensitivity to visual, auditory or environmental input (Robertson and Baron-Cohen 2017). Some scholars have noted that more subjective perceptions such as atmospheric changes and spiritual experiences are also strongly represented in this population (Bogdashina 2013; Hills, Clapton, and Dorsett 2016, 2019; Shayew 2019; Stillman 2006; Weirauch 2013). It is not inconceivable therefore, that people with communication, intellectual or developmental impairments may hold compensatory abilities, by way of a heightened internal sensitivity congruent to their lived experience. In other words, someone whose life context affords them an ability for communication beyond typical language constructs, a heightened sensitivity to subliminal perceptions, and a generous proportion of time spent in silence and solitude, is likely to experience an extraordinary spirituality. This is consistent with data from this research:

I have access to a deeper place than words can go, and my spirituality helps me do that. (Participant 7)

It (spirituality) is now a thing of longevity instead of a fleeting moment that passes so quickly. It is a thing of underworld. It is my base rate of being 'here I am and here I will be' and I endure despite what the world does to me. (Participant 4)

The idea of heightened spiritual awareness amongst people with nonverbal autism is also represented in the nonverbal narrative literature where several authors have asserted that their life is divinely inspired for a predetermined mission, to bring a specific message to the world (e.g. Ball 2001; Cochran 2011; Lee and Marquez 2011; Weirauch 2013). Some have understood that because of their autism, they somehow have an increased ability to facilitate God's message of love (e.g. Ball 2001; Bonker and Breen 2011; Hale and Hale 1999; Lee and Marquez 2011; Weirauch 2013). Consistent with this understanding, participants in this study concurred:

Yes, it (spirituality) is protection and transformation and respect and love... I'm a good person and I love to help people. (Participant 4),

I would want others to give themselves permission to explore their own spirituality and I would want others to expect to find spirit in people they might have overlooked. (Participant 7)

Many authors have also spoken about a personal and deep spirituality (Ball 1999, 2001; Bonker and Breen 2011; Burns and Wambua 2009; Cochran 2011; Cullen and Ricker 2016; Goddard and Goddard 2012; Hale and Hale 1999; Lee and Marquez 2011; McKinley 2011; Rocha and Jorde 1995; Weirauch 2013), recounting experiences of a spiritual nature irrespective of any exposure to formal religion. Authors often 
expressed always knowing God (e.g. Ball 1999, 2001; Cullen and Ricker 2016; Lee and Marquez 2011; McKinley 2011; Weirauch 2013). This is consistent with the interview data:

I know the God is real because I have seen Him. I saw the vision of God - a halo on his head in the sun right next to me. It was very bright to look at. Up in the great heavenly place I tell my Father to look after my mum and dad and friends. (Participant 2)

Authors also described an ability to communicate with God without typical language (Ball 1999, 2001; Bonker and Breen 2011; Burns and Wambua 2009; Lee and Marquez 2011; McKinley 2011; Rocha and Jorde 1995; Weirauch 2013). Some discerned that it is their inability to communicate orally that has a significant impact on their personal spiritual experiences (e.g. Ball 2001; Burns and Wambua 2009; Cochran 2011; McKinley 2011; Weirauch 2013), a concept also validated by data from this study. Furthermore, parents of children with nonverbal autism have reported evidence of their child possessing a mature and developed spirituality which seems unrelated to any formal religious background (e.g. Blaier-Stein 2013; Bonker and Breen 2011; Cochran 2011; Cullen and Ricker 2016; Goddard and Goddard 2012; Lee and Marquez 2011; Rocha and Jorde 1995; Weirauch 2013).

\section{Conclusion}

Stillman $(2008,40)$ conjectured that 'There are many autistics [sic] who are silently awaiting the opportunity to share their gifts with us', and that 'those who live in silence are often keepers of extraordinary wisdom' (Stillman 2010, 130; see also Hills, Clapton, and Dorsett 2016, 2019; Rohr 2015). Traditionally, it has been identified that such wisdom is born and developed through personal behaviours that include self-reflection, self-determination, self-awareness and the ability to listen more intently than to speak (Karunamuni and Weerasekera 2017; Vandekerckhove 2016). These qualities are developed through reflective practices, which, by their very nature, require time in 'solitude and silence', such as is the life context of individuals with nonverbal autism.

This research explored the spirituality of a group of people with a particular social experience. Data suggest that the unique life context of this population could be conducive to the development of a mature and well-considered spirituality. Ancient and contemporary wisdom traditions concur that a lifestyle inclusive of time and space for reflection, mindfulness and contemplation develops spiritual aptitude and the ability for heightened experience. This experience need not be in relation to any formal religious tradition or teaching.

The rich spiritual experiences of people with nonverbal autism are clearly an important but relatively unexplored reality of the autistic experience. This discussion suggests that there is much this group has to offer society regarding new ways to encounter and express spirituality. As Shayew pondered:

What if the autistic state of mind and way of viewing the world represents, not a defect that we must correct, but an evolutionary step up? What if millions of autistic individuals are here to show us neuro-typicals a different way, a way of living that can potentially be more spiritually satisfying, more deeply connected, more co-creative and profoundly meaningful than we can imagine? (Shayew 2019, para. 1) 
The possibility of people with nonverbal autism leading the way to a long-forgotten spiritual aptitude developed by a lifestyle that includes silence and solitude is not unrealistic. The key to the realisation of this possibility will lie in the ability of neurotypical people to invest energy into learning to communicate differently. Perhaps, just perhaps, 'those of us who are always waiting for our chance to talk,' have a great deal to learn from those with little or no speech who, by virtue of their life circumstance, are more able to 'listen more intently' (Crossley n.d., para. 8). Therefore, rather than being viewed as a deficit in need of correction, in this context nonverbal autism can be seen as a gift (Bogdashina 2013; Shayew 2019; Stillman 2006; Weirauch 2013) - a gift that is of benefit to the recipient, but also of interest and benefit to others.

We hope that this discussion will contribute to expanding the acceptance of non-traditional ways of learning and expressing spirituality. And that people with nonverbal autism will be embraced as intelligent, sensitive and gifted carriers of the image of God.

\section{Disclosure statement}

No potential conflict of interest was reported by the authors.

\section{Notes on contributors}

Karenne Hills is a Ph.D. candidate at Griffith University, Australia. She has special interests in theological and spiritual perspectives regarding people with disability and has presented her work at national and international conferences.

Prof Jayne Clapton is an Adjunct Professor in the School of Human Services and Social Work, Griffith University, Australia. Her book A Transformatory Ethic of Inclusion (2009) presents her seminal research of the relationship between ethics, theology, inclusion, belonging and disability.

Dr Pat Dorsett is a Senior Lecturer in the School of Human Services and Social Work, Griffith University, Australia. She has published widely in the fields of disability and rehabilitation, and has a particular interest in the lived experience of people in the context of life challenges.

\section{References}

American Psychiatric Association. 2013. Diagnostic and Statistical Manual of Mental Disorders 5th edn. DSM-5. Washington, DC: American Psychiatric Association.

Ball, Marshall Stewart. 1999. Kiss of God. The Wisdom of a Silent Child. Deerfield Beach: Health Communications.

Ball, Marshall Stewart. 2001. A Good Kiss. New York: Pocket Books.

Barber, Christopher. 2016. "What Can I Gift Myself? A Meeting Between Christian and Buddhist Forms of Meditation from an Autistic Perspective." Journal for the Study of Spirituality 5 (2): 157-169. doi:10.1179/2044024315Z.00000000048A.

Biklen, Douglas. 1993. Communication Unbound: How Facilitated Communication is Challenging Traditional Views of Autism and Ability-Disability. New York: Teachers College Press.

Biklen, Douglas. 2005. Autism and the Myth of the Person Alone. New York: University Press.

Bitton-Ashkelony, Brouria. 2012. "'More Interior Than the Lips and the Tongue': John of Apamea and Silent Prayer in Late Antiquity." Journal of Early Christian Studies 20 (2): 303-331. doi:10. 1353/earl.2012.0011.

Blaier-Stein, Shirley. 2013. Autism Mom. Stein Education Services.

Blumberg, Stephen, Mathew Bramlett, Michael Kogan, Laura Schieve, Jessica Jones, and Michael Lu. 2013. Changes in Prevalence of Parent-Reported Autism Spectrum Disorder in School-Aged 
US Children: 2007 to 2011-2012. National Health Statistics Reports No. 65. Hyattsville: National Center for Health Statistics.

Bogdashina, Olga. 2013. Autism and Spirituality; Psyche, Self and Spirit in People on the Autism Spectrum. Philadelphia: Jessica Kingsley.

Bonker, Elizabeth M., and Virginia G. Breen. 2011. I am in Here: The Journey of a Child with Autism who Cannot Speak but Finds her Voice. Grand Rapids: Revell.

Brock, B. 2009. “Autism, Care and Christian Hope." Journal of Religion, Disability \& Health 13 (1): 7-28. doi:10.1080/15228960802581404.

Burns, Michele Pierce, and Danson Mandela Wambua. 2009. Danson. Pittsburgh: St. Lynn's Press.

Bustion, Olivia. 2017. "Autism and Christianity: An Ethnographic Intervention." Journal of the American Academy of Religion 85 (3): 653-681.

Campolo, Tony, and Mary Albert Darling. 2007. The God of Intimacy and Action. San Francisco, CA: Jossey-Bass.

Centers for Disease Control and Prevention. 2018. "Prevalence of Autism Spectrum Disorder Among Children Aged 8 Years - Autism and Developmental Disabilities Monitoring Network, 11 Sites, United States, 2014." MMWR. Surveillance Summaries 67 (6): 1-23. Accessed 27 June 2019. https://www.cdc.gov/mmwr/volumes/67/ss/ss6706a1.htm?s_cid= ss6706a1_w.

Cochran, Sean. 2011. Lions, Bears, \& Math. Kindle word version. https://www.amazon.com.

Crossley, Rosemary. n.d. How Did We Get Here?. Caulfield: Anne McDonald Centre.

Cullen, Tahni, and Cheryl Ricker. 2016. Josiah's Fire. Racine: BroadStreet.

Dearey, Paul. 2009. "Do the Autistic Have a Prayer?" Journal of Religion, Disability and Health 13 (1): 40-50. doi:10.1080/15228960802581420.

The Economist. 2018. "Silence as Presence. Obituary: Thomas Keating Died on October 25th." The Economist, December 18: 122. Accessed 13 February 2019. https://www.economist.com/ obituary/2018/12/22/obituary-thomas-keating-died-on-october-25th.

Fleischmann, Arthur, and Carly Fleischmann. 2012. Carly's Voice. New York: Touchstone.

Gandhi, Punita. 2009. "Understanding the Nature of Spiritual Experiences: A Qualitative Study." PhD diss., University of Indiana.

Garrigou-Lagrange, Reginald. 2014. Vol. 1 of the Three Ages of the Interior Life. Prelude of Eternal Life. Trans Timothea Doyle. London: Catholic Way.

Goddard, Peyton, and Dianne Goddard. 2012. I am Intelligent. Skirt!: Guilford.

Grandin, Temple. 2011. The Way I See it. A Personal Look at Autism and Asperger's. 2nd edn. Arlington: Future Horizons.

Hale, Mary Jane Grey, and Charles Martel Hale. 1999. I Had no Means to Shout!. Bloomington: 1st Book Library.

Harmless, William. 2008. Mystics. New York: Oxford University Press.

Harshaw, Jill. 2012. “Autism and Love. Learning What Love Looks Like - A Response.” Practical Theology 5 (3): 279-285. doi:10.1558/prth.v5i3.279.

Hills, Karenne, Jayne Clapton, and Pat Dorsett. 2016. “Towards an Understanding of Spirituality in the Context of Non-verbal Autism: A Scoping Review.” Journal of Disability and Religion 20: 265-290. doi:10.1080/23312521.2016.1244501.

Hills, Karenne, Jayne Clapton, and Pat Dorsett. 2019. "Spirituality in the Context of Nonverbal Autism: Practical and Theological Considerations." Practical Theology 12 (2): 186-197. doi:10. 1080/1756073X.2019.1592927.

Hills, Karenne, and John Meteyard. 2013. "Disability: A Fresh Approach to an Old Dilemma." Journal of Religion, Disability and Health 17: 62-72. doi:10.1080/15228967. 2013.753715 .

Hoffman, Thomas. 1997. "Moving Beyond Dualism: A Dialogue with Western European and American Indian Views of Spirituality, Nature, and Science." The Social Science Journal 34 (4): 447-460. doi:10.1016/S0362-3319(97)90004-5.

Isanon, Abe. 2001. Spirituality and the Autism Spectrum. Of Falling Sparrows. London: Jessica Kingsley. 
Jack, Allison, and Kevin Pelphrey. 2017. “Annual Research Review: Understudied Populations Within the Autism Spectrum - Current Trends and Future Directions in Neuroimaging Research." Journal of Child Psychology and Psychiatry 58 (4): 411-435. doi:10.1111/jcpp.12687. Jantzen, Grace. 2000. Julian of Norwich. New York: Paulist Press.

Karunamuni, Nandini, and Rasanjala Weerasekera. 2017. "Theoretical Foundations to Guide Mindfulness Meditation: A Path to Wisdom.” Current Psychology, 1-20. Advance online publication. doi:10.1007/s12144-017-9631-7.

Keating, Thomas. 2005. Manifesting God. New York: Lantern Books.

Kenny, Lorcan, Caroline Hattersley, Bonnie Molins, Carole Buckley, Carol Povey, and Elizabeth Pellicano. 2016. "Which Terms Should be Used to Describe Autism? Perspectives from the UK Autism Community.” National Autistic Society 20: 442-462. doi:10.1177/ 1362361315588200 .

Lee, Grace Barkley, and Lyrica Mia Marquez. 2011. AWEtizm: A Hidden Key to our Spiritual Magnificence. Wickenburg: Chrysalis Gold LLC.

Lepherd, Laurence. 2015. "Spirituality: Everyone Has It, But What is It?" International Journal of Nursing Practice 21 (5): 566-574. doi:10.1111/ijn.12285.

McKinley, Seth. 2011. God Saved me from Silence. Maitland, FL: Xulonpress.

Meji, Obara. 2017. "The Spirituality of Language". Embracing Spirituality. Accessed 11 February, 2019. https://www.embracingspirituality.com/2017/09/11/the-spirituality-of-language.

Merriam-Webster. 2019a. “Silence.” Merriam-Webster's Online Dictionary. http://www.merriamwebster.com/dictionary/silence.

Merriam-Webster. 2019b. “Solitude." Merriam-Webster's Online Dictionary. http://www.merriamwebster.com/dictionary/solitude.

Neeti, Rana. 2015. "Mindfulness and Loving-Kindness Meditation: A Potential Tool for Mental Health and Subjective Well-Being." Indian Journal of Positive Psychology 6 (2): 189-196. https://www.questia.com/library/journal/1P3-3760120861/mindfulness-and-loving-kindnessmeditation-a-potential.

Norbury, Courtenay, Debbie Gooch, Charlotte Wray, Gillian Baird, Tony Charman, Emily Simonoff, George Vamvakas, and Andrew Pickles. 2016. "The Impact of Nonverbal Ability on Prevalence and Clinical Presentation of Language Disorder: Evidence from a Population Study." Journal of Child Psychology and Psychiatry 57 (11): 1247-1257. doi:10.1111/jcpp.12573.

Pinchevski, Amit. 2005. By Way of Interruption: Levinas and the Ethics of Communication. Pittsburgh: Duquesne University Press.

Pitre, Brant. 2009. "Spiritual Theology: Introduction". Supplemental Material. Spiritual Theology. Christian Prayer and the Three Stages of the Spiritual Life. Harahan: Catholic Productions. Compact disc. https://store.catholicproductions.com/.

Reinert, Katia Garcia, and Harold Koenig. 2013. "Re-Examining Definitions of Spirituality in Nursing Research.” Journal of Advanced Nursing 69 (12): 2622-2634. doi:10.1111/jan.12152.

Robertson, Caroline, and Simon Baron-Cohen. 2017. "Sensory Perception in Autism." Nature Reviews Neuroscience 18 (11): 671-684. doi:10.1038/nrn.2017.112.

Rocha, Adriana, and Kristi Jorde. 1995. A Child of Eternity. New York: Ballantine Books.

Rohr, Richard. 2015. What the Mystics Know: Seven Pathways to Your Deeper Self. New York: Crossroad.

Rudy, Lisa Jo. 2017. “Autism and Spirituality.” Verywellhealth, February 21. http://autism.about. com/.

Schiffhorst, Gerald. 2011. “Thomas Merton's Desert Spirituality.” Cithara 50 (2): 3-13. https:// www.questia.com/library/journal/1P3-2373201921/thomas-merton-s-desert-spirituality.

Shayew, Lori. 2019. “The Gifts of Autism.” Book Description. http://thegiftsofautism.com/Home. php.

Siegel, Matthew. 2018. "The Severe End of the Spectrum: Insights and Opportunities from the Autism Impatient Collection (AIC)." Journal of Autism and Developmental Disorders 48: 3641-3646. doi:10.1007/s10803-018-3731-6. 
Sorokowska, Agnieszka, and Maciej Karwowski. 2017. "No Sensory Compensation for Olfactory Memory: Differences between Blind and Sighted People." Frontiers in Psychology 8: 2127. doi:10.3389/fpsyg.2017.02127.

Starr, Mirabai. 2003. Dark Night of the Soul. New York: Penguin Putnam.

Stillman, William. 2006. Autism and the God Connection: Redefining the Autistic Experience Through Extraordinary Accounts of Spiritual Giftedness. Naperville: Sourcebooks.

Stillman, William. 2008. The Soul of Autism. Franklin Lakes: New Page Books.

Stillman, William. 2010. The Autism Prophecies. Franklin Lakes: Career Press.

Stone, Wendy, and Paul Yoder. 2001. "Predicting Spoken Language Level in Children with Autism Spectrum Disorders.” Autism 5 (4): 341-361. doi:10.1177/1362361301005004002.

Swinton, John. 2012. "Reflections on Autistic Love: What Does Love Look Like?" Practical Theology 5 (3): 259-278. doi:10.1558/prth.v5i3.259.

Tacey, David. 2015. "Spiritual Connectedness and Healing." PACJA 3 (1). http://pacja.org.au/.

Underhill, Evelyn. 2015. The Mystics of the Church. New York: Aeterna Press.

Vandekerckhove, Bieke. 2016. The Taste of Silence: How I Came to Be at Home with Myself. Translated by Rudolf Van Puymbroeck. Collegeville: Liturgical Press.

Vosseller, Elizabeth. 2018. "Open Letter to ASHA by Elizabeth Vosseller." Growing Kids Therapy, June 28. Accessed 14 March 2019. https:/growingkidstherapy.wordpress.com/2018/06/28/openletter-to-asha-by-elizabeth-vosseller/.

Weirauch, Wolfgang, ed. 2013. Inside an Autistic World. Translated by Mathew Barton. Forest Row, England: Temple Lodge.

Yamane, David. 2000. “Narrative and Religious Experience.” Sociology of Religion 61 (2): 171-189. doi:10.2307/3712284. 